\title{
Avaliação econômica da terminação de bovinos de corte em pastagem irrigada
}

[Economic evaluation of finishing beef cattle on irrigated pasture]

\author{
J.C.R. Soares ${ }^{1}$, J.O.J. Barcellos ${ }^{1 *}$, L.A.V. Queiroz Filho ${ }^{1}$, R.P. Oaigen ${ }^{2}$, M.E.A. Canozzi ${ }^{1}$, \\ C.M. Camargo $^{1}$, L.C.D. Drumond ${ }^{3}$, J. Braccini Neto ${ }^{1}$ \\ ${ }^{1}$ Faculdade de Agronomia- Universidade Federal do Rio Grande do Sul - UFRGS - Porto Alegre, RS \\ ${ }^{2}$ Universidade Federal do Pampa - Unipampa - Uruguaiana, RS \\ ${ }^{3}$ Universidade Federal de Viçosa - UFV - Campus Rio Parnaíba - Rio Parnaíba, MG
}

\begin{abstract}
RESUMO
Foi avaliada a viabilidade econômica de três sistemas de produção por meio da mensuração dos custos de produção e da análise dos indicadores financeiros. Os três sistemas (S1, S2 e S3), situados na fronteira oeste do Rio Grande do Sul, foram avaliados no período de outubro de 2010 a outubro de 2011. A pastagem estabelecida no S1 foi de azevém (Lolium multiflorum Lam) e trevo branco (Trifolium repens Lam); no S2, trevo branco, trevo vermelho (Trifolium pratense Lam), cornichão (Lotus corniculatus Lam), azevém e aveia preta (Avena strigosa Schreb); e no S3, azevém, cornichão, trevo branco e trevo vermelho. Os animais foram pesados na entrada e na saída das pastagens. A coleta de dados para mensuração do custo foi realizada mensalmente utilizando-se planilhas apropriadas. As produtividades foram de 369, 772 e $637 \mathrm{~kg} / \mathrm{ha}$ para os sistemas S1, S2 e S3, respectivamente. O S2 apresentou o maior custo total (R\$2.101,59/ha), enquanto o menor foi obtido pelo S1 (R\$ 1.626,93/ha). Na análise do custo operacional médio dos três sistemas, os itens que apresentaram maiores valores foram a implantação de pastagem, a energia elétrica, a manutenção da pastagem e a depreciação. Quanto às margens, os sistemas S1, S2 e S3 apresentaram, respectivamente, R\$ 33,46, 1.162,55 e 701,01/ha para margem bruta; R\$ $63,51,955,40$ e 541,05/ha para margem operacional; e $\mathrm{R} \$-583,18,291,61$ e -28,99/ha para lucro total. A rentabilidade foi de $-0,47,4,37$ e 3,01\% e a lucratividade foi de $-5,94,39,92$ e 27,38\% para o S1, S2 e S3, respectivamente. A irrigação de pastagens para terminação de bovinos é viável economicamente, no entanto a sua adoção deve sempre visar a altas produtividades zootécnicas devido ao seu elevado custo de produção.
\end{abstract}

Palavras-chave: custo de produção, intensificação, pivô central, resultado econômico

\begin{abstract}
The economic viability of three systems of production was evaluated through the measurement of costs and analysis of financial indicators. The three systems (S1, S2 and S3), located on the Western Border of Rio Grande do Sul, were evaluated from October 2010 to October 2011. The pasture established is S1 was ryegrass (Lolium multiflorum Lam) and white clover (Trifolium repens Lam), in S2, white clover, red clover (Trifolium pratense Lam), Bird's-foot trefoil (Lotus corniculatus Lam), ryegrass and oats (Avena strigosa Schreb), and in S3, ryegrass, birdsfoot trefoil, white clover and red clover. The animals were weighed before and after the pastures. Data collection was conducted monthly, using spreadsheets suitable for the measurement of production cost. Productivities were 369, 772 and $637 \mathrm{~kg} / \mathrm{ha}$ for systems $S 1, S 2$ and S3, respectively. S2 had the highest total cost ( $R \$ 2101.59 /$ ha), while the lower was obtained by $S 1(R \$ 1626.93 / \mathrm{ha})$. In the analysis of the average operating costs, items that showed the highest values were the establishment of pasture, electricity, maintenance of pasture and depreciation. As for margins, the systems S1, S2, and S3 were, respectively, $R \$ 33.46,1162.55$ and $701.01 /$ ha for gross margin; $R \$-63.51,955.40$ and $541.05 \mathrm{ha}^{-1}$ for operating margin; and $R \$-583.18,-28.99$ and $291.61 \mathrm{ha}^{-1}$
\end{abstract}

Recebido em 6 de fevereiro de 2014

Aceito em 25 de novembro de 2014

*Autor para correspondência (corresponding author)

E-mail: julio.barcellos@ufrgs.br 
for total profit. The return was $-0.47,4.37$ and $3.01 \%$ and profitability was $-5.94,39.92$ and $27.38 \%$ for the S1, S2 and S3 respectively. The positive result found in the financial evaluation of the three systems studied indicates the economic viability of irrigated pasture in finishing cattle. Irrigation of pasture for finishing cattle is economically feasible, however, its application should always aim high yields husbandry due to their high cost of production.

Keywords: production cost, intensification, central pivot, economic result

\section{INTRODUÇÃO}

Nos últimos anos, o uso crescente de tecnologias mais intensivas tem permitido aumentar a produtividade na bovinocultura de corte. No Brasil, tal incremento em sistemas de engorda de bovinos é dependente da utilização de técnicas que melhorem o principal recurso alimentar utilizado no país - as pastagens - para tornar a atividade mais competitiva. Entretanto, o aumento na produtividade nem sempre é sinônimo de lucratividade, devendo sempre ser analisado pontualmente cada sistema produtivo (Costa et al., 2006).

Entre as tecnologias, a irrigação do pasto elimina o efeito do estresse hídrico das plantas e minimiza a estacionalidade produtiva ao longo do ano (Azevedo e Saad, 2009). Por isso, constitui, possivelmente, uma das principais alternativas para a produção intensiva de carne em regiões onde a temperatura e a luminosidade não são fatores limitantes (Drumond e Aguiar, 2005).

A introdução de métodos mais intensivos de produção gera aumento dos custos diretos e dos riscos, portanto existe a necessidade da avaliação do impacto financeiro no sistema por meio de estudos de viabilidade econômica. Nas atividades zootécnicas, essa análise é um procedimento fundamental para gestão do sistema, por permitir melhor predição e maior conhecimento dos resultados (Pacheco et al., 2006; Silva et al., 2010).

A partir desse contexto, o trabalho foi conduzido para avaliar a viabilidade econômica de três sistemas produtivos, especializados na terminação de bovinos de corte, em pastagens cultivadas, irrigadas com pivô central, na fronteira oeste do estado do Rio Grande do Sul.

\section{MATERIAL E MÉTODOS}

Foram avaliados, entre outubro de 2010 e outubro de 2011, três sistemas de terminação de bovinos de corte (S1, S2 e S3), com 99ha de pastagens hibernais irrigadas por pivô central, localizados na fronteira oeste do Rio Grande do Sul. Nessa região, o clima característico é o tipo subtropical (cfa), com verões muito quentes, estiagens frequentes nos meses de novembro a fevereiro (Ughini, 2005) e balanço hídrico negativo em alguns dias do ano (Instituto..., 2009).

No sistema 1 (S1), a pastagem foi implantada em março de 2010 com azevém (Lolium multiflorum Lam) e trevo branco (Trifolium repens Lam), sendo o primeiro predominante durante o período de avaliação. Na implantação da pastagem, foram utilizados $400 \mathrm{~kg} / \mathrm{ha}$ de adubo MAP (monoamônio fosfato), e na manutenção um total de $200 \mathrm{~kg} / \mathrm{ha}$ de ureia (45-00-00) aplicado duas vezes durante o ano. Foram utilizados machos castrados com idade de 24 a 36 meses de idade e vacas de descarte, ambos com predomínio da raça Braford.

Já no sistema 2 (S2), a pastagem foi estabelecida em março de 2010, com as espécies de trevo branco, trevo vermelho (Trifolium pratense Lam), cornichão (Lotus corniculatus Lam), azevém e aveia preta (Avena strigosa Schreb). No estabelecimento, foram utilizados $240 \mathrm{~kg} / \mathrm{ha}$ de NPK (05-25-25) e 300kg/ha de MAP, além de uma aplicação de $100 \mathrm{~kg} / \mathrm{ha}$ de ureia (45-00-00) para manutenção. No verão, houve um predomínio do trevo branco sobre as demais espécies em toda área. Nesse sistema, foram manejados machos castrados de 24 a 36 meses de idade da raça Braford e suas cruzas.

No terceiro sistema (S3), também em março de 2010, a pastagem estabelecida foi de azevém, cornichão, trevo branco e trevo vermelho. Foi utilizado adubo NPK (04-22-22) na quantidade de $230 \mathrm{~kg} / \mathrm{ha}$ para estabelecimento da pastagem, e 
para manutenção foi aplicado, em dois momentos, um montante de $190 \mathrm{~kg} / \mathrm{ha}$ de ureia (45-00-00). Foram terminados machos castrados (novilhos) e novilhas de 18 a 24 meses de idade, oriundos de cruzamento com as raças Angus e Hereford. Os trevos predominaram no período do verão e do outono. Esse sistema foi o único que não teve a necessidade de retirada dos animais para manutenção da pastagem. Nos demais, foi necessário retirar os bovinos no período do outono para manutenção delas.

Os sistemas de irrigação utilizados eram do tipo "pivot central" e apresentavam entre cinco e 10 anos de uso. Além disso, as regas eram acionadas entre $21 \mathrm{~h} 30$ e seis horas para maximizar o aproveitamento do desconto no preço da energia elétrica para produtores irrigantes.

A avaliação econômica iniciou com um diagnóstico dos sistemas, seguido da coleta mensal dos dados e do processamento em planilhas eletrônicas do Microsoft Excel $^{\circledR}$. O custo dos insumos e das operações para formação das pastagens foi calculado com base no levantamento da quantidade e do respectivo valor praticado na época do experimento. $\mathrm{O}$ custo final da implantação das pastagens foi dividido por uma vida útil de três anos.

As metodologias utilizadas para a mensuração dos parâmetros zootécnicos e econômicos foram baseadas nas recomendações de diversos autores (Matsunaga et al., 1976; Franke e Dorfman, 1998; Bonaccini, 2000; Flores et al., 2006; Nogueira, 2007), sendo consolidados os seguintes parâmetros: produção animal (PA; kg) $=($ pesos das saídas + peso do estoque final $)-$ (peso do estoque inicial + pesos das entradas + pesos das mortes); produtividade $=$ produção / área; carga animal $=$ peso médio $\mathrm{x} \mathrm{n}^{\circ}$ animais / área; receita total $(\mathrm{RT} ; \mathrm{R} \$)=$ produção $\mathrm{x}$ valor médio (kg vivos); custo desembolsado (CD; R\$) = custo variável $(\mathrm{CV})+$ custo fixo $(\mathrm{CF})$ sem depreciação; custo operacional $(\mathrm{CO} ; \mathrm{R} \$)=\mathrm{CV}+$ $\mathrm{CF}$ com depreciação; depreciação $(\mathrm{D} ; \mathrm{R} \$)=$ (valor inicial - valor final) / vida útil em anos; custo total $(\mathrm{CT} ; \mathrm{R} \$)=\mathrm{CO}+$ custo de oportunidade da terra (COT) e capital (COC). O COT foi arbitrado em $40 \mathrm{~kg}$ de novilho/hectare/ano, enquanto o COC foi calculado pela opção de investimento na poupança à taxa de $6 \%$ ao ano. Foi considerado $o$ custo médio dos valores desembolsados no período da atividade.

Após a obtenção desses parâmetros, foram calculados os seguintes indicadores: margem bruta $(\mathrm{MB} ; \mathrm{R} \$)=$ receita total $-\mathrm{CD}$; margem operacional $(\mathrm{MO} ; \mathrm{R} \$)$ = receita total - $\mathrm{CO}$; lucro total $(\mathrm{LT} ; \mathrm{R} \$)=$ receita total $-\mathrm{CT}$; lucratividade $($ LUC; \%) $=$ MO / receita total $\mathrm{x} 100$; rentabilidade do capital investido (RCI; \%) = MO / capital investido x 100; ponto de equilíbrio físico $(\mathrm{PEF} ; \mathrm{kg})=\mathrm{CF} /$ (receita unitária - custo fixo unitário); ponto de equilíbrio monetário $(\mathrm{PEM} ; \mathrm{R} \$)=\mathrm{PEF} \times$ receita unitária; payback $(\mathrm{PB} ;$ anos $)=$ capital investido / MB; e capital investido, que é a soma do valor do equipamento de irrigação ( $\mathrm{R} \$$ 485.000,00), dos animais (estoque inicial e entradas), da pastagem e dos custos operacionais. Todos os indicadores foram divididos pela área (99ha) e pela respectiva produção (PA) em kg de peso vivo.

\section{RESULTADOS}

Os sistemas de produção avaliados apresentaram valores absolutos diferentes para os parâmetros zootécnicos e financeiros. Além disso, demonstraram os resultados da intensificação dos processos produtivos refletidos pelos parâmetros de elevada produtividade e carga animal (Tab. 1).

A avaliação financeira realizada foi com base na análise dos parâmetros econômicos dos três sistemas produtivos. $\mathrm{O} \mathrm{S} 2$ foi o único que apresentou resultados positivos para os parâmetros que demonstram a viabilidade econômica da tecnologia em estudo ( $\mathrm{MB}, \mathrm{MO}$, LT, LUC e RCI).

Os valores encontrados para CT de produção foram altos devido aos custos da tecnologia de irrigação (Tab. 2) em relação aos custos de outras tecnologias de produção. O maior CT foi identificado no $\mathrm{S} 2$, seguido pelo $\mathrm{S} 3$ e $\mathrm{S} 1$, sendo o percentual mais significativo atribuído aos custos de oportunidade, o que representa, em relação ao CT, $30,4,31,6$ e $28,4 \%$ para S1, S2 e S3, respectivamente. 
Avaliação econômica...

Tabela 1. Parâmetros zootécnicos e econômicos da terminação de bovinos em pastagens irrigadas

\begin{tabular}{|c|c|c|c|c|}
\hline \multirow[b]{2}{*}{ Parâmetros } & \multirow[b]{2}{*}{ Unidade } & \multicolumn{3}{|c|}{ Sistema de produção } \\
\hline & & S1 & S2 & S3 \\
\hline \multicolumn{5}{|c|}{ Zootécnicos } \\
\hline Área & ha & 99 & 99 & 99 \\
\hline Produção & $\mathrm{kg}$ & 36.513 & 76.428 & 63.101 \\
\hline Produtividade & $\mathrm{kg} / \mathrm{ha}$ & 369 & 772 & 637 \\
\hline Carga animal média & $\mathrm{kg} / \mathrm{ha} / \mathrm{mês}$ & 619,3 & 934,1 & 864,6 \\
\hline Ganho médio diário & $\mathrm{kg} / \mathrm{cab} / \mathrm{dia}$ & 0,789 & 0,831 & 0,671 \\
\hline \multicolumn{5}{|c|}{ Econômicos } \\
\hline Receita total & $\mathrm{R} \$ / \mathrm{ha}$ & $1.069,57$ & $2.393,20$ & $1.975,87$ \\
\hline Margem bruta & $\mathrm{R} \$ / \mathrm{ha}$ & 33,46 & $1.162,55$ & 701,01 \\
\hline Margem operacional & $\mathrm{R} \$ / \mathrm{ha}$ & $-63,51$ & 955,40 & 541,05 \\
\hline Lucro total & $\mathrm{R} \$ / \mathrm{ha}$ & $-583,18$ & 291,61 & $-28,99$ \\
\hline Capital investido & $\mathrm{R} \$ / \mathrm{ha}$ & $13.540,17$ & $21.838,77$ & $17.946,83$ \\
\hline Receita total & $\mathrm{R} \$ / \mathrm{kg}$ & 2,90 & 3,10 & 3,10 \\
\hline Custo desembolsado & $\mathrm{R} \$ / \mathrm{kg}$ & 2,81 & 1,59 & 2,00 \\
\hline Custo operacional & $\mathrm{R} \$ / \mathrm{kg}$ & 3,07 & 1,86 & 2,25 \\
\hline Custo total & $\mathrm{R} \$ / \mathrm{kg}$ & 1,34 & 0,86 & 0,89 \\
\hline Margem bruta & $\mathrm{R} \$ / \mathrm{kg}$ & 0,09 & 1,51 & 1,10 \\
\hline Margem operacional & $\mathrm{R} \$ / \mathrm{kg}$ & $-0,17$ & 1,24 & 0,85 \\
\hline Lucro total & $\mathrm{R} \$ / \mathrm{kg}$ & $-1,58$ & 0,38 & $-0,05$ \\
\hline Rentabilidade no período & $\%$ & $-0,47$ & 4,37 & 3,01 \\
\hline Lucratividade no período & $\%$ & $-5,94$ & 39,92 & 27,38 \\
\hline Ponto equilíbrio monetário & $\mathrm{R} \$ / \mathrm{ha}$ & -- & $1.168,50$ & $1.134,51$ \\
\hline Ponto equilíbrio físico & $\mathrm{kg} / \mathrm{ha}$ & -- & 377 & 366 \\
\hline Payback & Anos & -- & 4,21 & 6,99 \\
\hline
\end{tabular}

Tabela 2. Custos de produção na terminação de bovinos em pastagens irrigadas

\begin{tabular}{lcccccc} 
& \multicolumn{7}{c}{ Sistema de produção } \\
\cline { 2 - 7 } & \multicolumn{2}{c}{$\mathrm{S} 1$} & \multicolumn{3}{c}{$\mathrm{S} 2$} & $\mathrm{~S} 3$ \\
\hline Custos de produção & $\mathrm{R} \$ / \mathrm{ha}$ & $\%$ & $\mathrm{R} \$ / \mathrm{ha}$ & $\%$ & $\mathrm{R} \$ / \mathrm{ha}$ & $\%$ \\
\hline Custos fixos & 492,80 & 30,3 & 911,57 & 43,4 & 729,57 & 36,4 \\
Implantação da pastagem & 317,16 & 19,5 & 638,36 & 30,4 & 503,55 & 25,1 \\
Mão de obra & 66,06 & 4,1 & 66,06 & 3,1 & 66,06 & 3,3 \\
Seguros & 12,61 & 0,8 & 0,00 & 0,0 & 0,00 & 0,0 \\
Depreciação & 96,97 & 6,0 & 207,15 & 9,9 & 159,96 & 8,0 \\
Custos variáveis & 640,29 & 39,4 & 526,23 & 25,0 & 705,26 & 35,2 \\
Energia elétrica & 276,61 & 17,0 & 359,44 & 17,1 & 290,06 & 14,5 \\
Manutenção & 89,51 & 5,5 & 28,41 & 1,4 & 0,00 & 0,0 \\
Produtos veterinários & 11,05 & 0,7 & 17,43 & 0,8 & 122,92 & 6,1 \\
Sal mineral & 21,82 & 1,3 & 11,64 & 0,6 & 42,78 & 2,1 \\
Manutenção pastagem & 241,30 & 14,8 & 109,31 & 5,2 & 249,49 & 12,4 \\
Custo desembolsado & $1.036,12$ & 63,7 & $1.230,65$ & 58,6 & $1.274,87$ & 63,6 \\
Custo operacional & $1.133,09$ & 69,6 & $1.437,80$ & 68,4 & $1.434,82$ & 71,6 \\
Custo de oportunidade & 493,84 & 30,3 & 663,79 & 31,6 & 570,04 & 28,4 \\
Custo total & $1.626,93$ & 100 & $2.101,59$ & 100 & $2.004,86$ & 100 \\
\hline
\end{tabular}

Com a finalidade de identificar as principais contas que compõem o custo operacional, foi realizada uma média dos três sistemas produtivos sem a contabilização do custo de oportunidade. Em ordem decrescente, os principais $\mathrm{CO}$ foram para implantação de pastagem, com $\mathrm{R} \$$ 486,35/ha (36\%); energia elétrica, com R\$ 308,70/ha (23\%); manutenção de pastagens, com R\$ 200,04/ha (15\%); depreciação, com R\$ $154,69 /$ ha $(12 \%)$; e mão de obra, com R\$ 
$66,06 /$ ha $(5 \%)$. Os demais custos referentes a produtos veterinários, manutenção geral, sal mineral e seguro somaram R\$119,39/ha (9\%).

O ponto de equilíbrio foi avaliado somente para os sistemas que obtiveram resultados positivos para margem operacional (S2 e S3). O PEF do S2 foi alcançado na produção de $37.317 \mathrm{~kg}$, representando uma exigência de produtividade na ordem de $377 \mathrm{~kg} /$ ha. Já o S3 alcançou o ponto de equilíbrio com produção de $36.231 \mathrm{~kg}$ e $366 \mathrm{~kg} / \mathrm{ha}$ de produtividade. Para o PEM, foram encontrados valores de $\mathrm{R} \$ 1.168,50 /$ ha para o S2 e $\mathrm{R} \$ 1.134,51 /$ ha para o S3, o que representa um valor unitário respectivo de $\mathrm{R} \$ 1,86 / \mathrm{kg}$ e $\mathrm{R} \$$ 2,25/kg (Fig. 1).
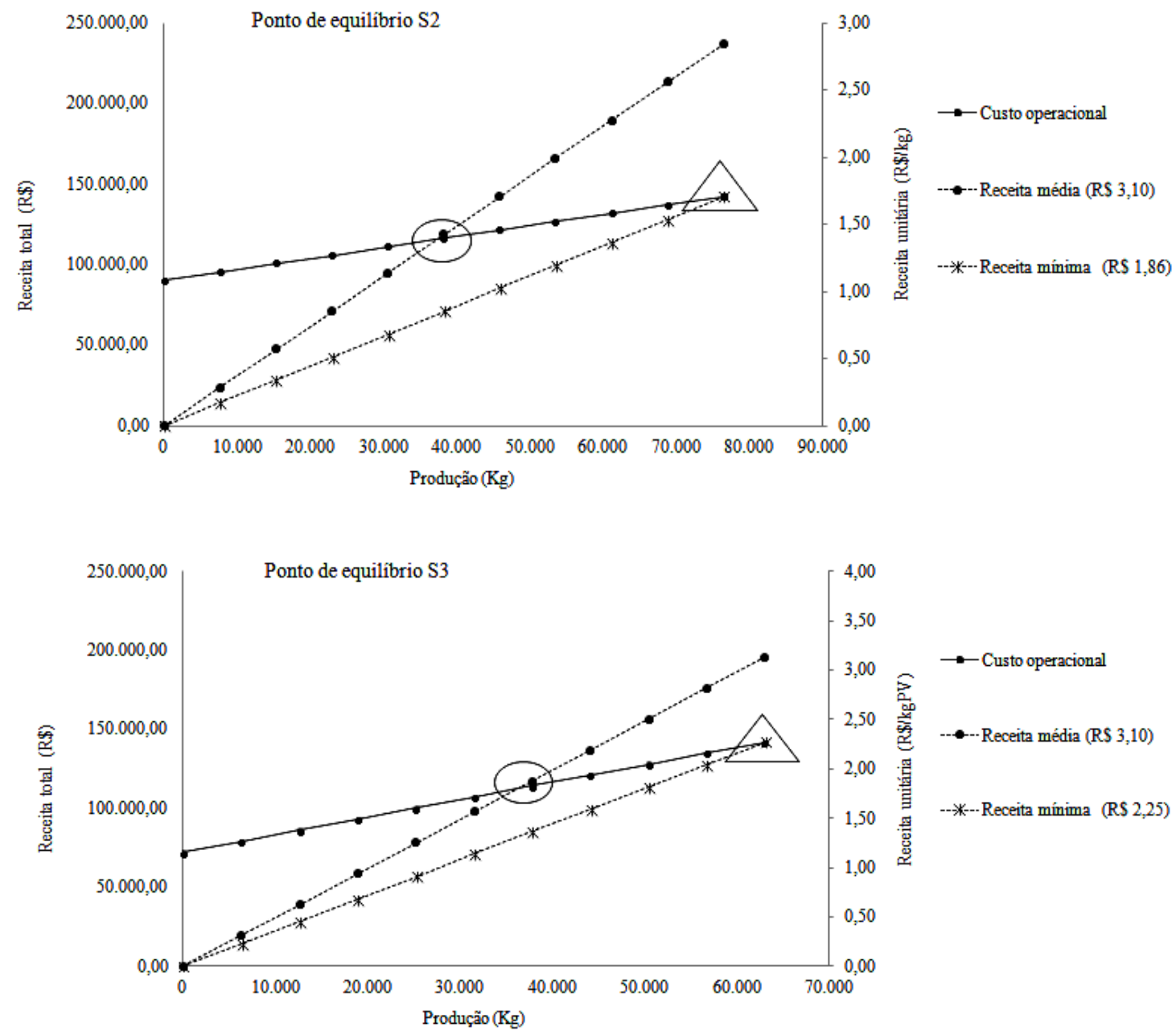

Figura 1. Análise do ponto de equilíbrio dos sistemas S2 e S3.

\section{DISCUSSÃO}

Os distintos parâmetros encontrados nos sistemas se devem, fundamentalmente, às características individuais, estratégicas e operacionais relacionadas a cada unidade estudada. Essa variação se justifica, principalmente, pelas diferenças relativas à categoria animal, à raça, ao tipo de forrageira utilizada e ao manejo imposto em cada um dos sistemas avaliados (Barbosa et al., 2010). Portanto, as comparações entre sistemas devem sempre ser realizadas com ressalvas, considerando a eficiência individual na utilização dos fatores de produção terra, capital, trabalho e conhecimento. 
Os maiores valores de produtividades foram registrados nos sistemas $\mathrm{S} 2$ e $\mathrm{S} 3$, consequência da maior eficiência no processo produtivo, da maior qualidade das pastagens utilizadas e das categorias animais com alto desempenho (novilhos de 24 meses). Já o S1 obteve a menor produtividade, devido, provavelmente, à utilização de vacas de descarte, categoria que possui menor desempenho (Restle et al., 1998), e à menor disponibilidade forrageira no período estival.

Quanto à qualidade forrageira, que tem forte influência no desempenho zootécnico dos animais, o S2 e o S3 apresentaram melhores valores médios para PB $(10,9 \%$ e $14,9 \%$, respectivamente) e FDN $(41,5 \%$ e $38,2 \%$, respectivamente). Já os valores obtidos pelo $\mathrm{S} 1$ $(9,9 \%$ para $\mathrm{PB}$ e $48,2 \%$ para FDN) podem servir como justificativa para os resultados encontrados no presente estudo.

Em relação ao ganho médio diário dos animais, obteve-se um desempenho de 0,789, 0,831 e $0,671 \mathrm{~kg}$, respectivamente, para os sistemas $\mathrm{S} 1$, S2 e S3. No entanto, o desempenho individual dos animais não refletiu os resultados globais do sistema de produção. Nesse sentido, a carga animal e a produtividade/ha foram eleitas para indicar a melhor relação sistema de produção versus eficiência.

Os resultados de produtividade dos sistemas foram superiores em comparação à média do Rio Grande do Sul, que é de 60 a $70 \mathrm{~kg} / \mathrm{ha}$, podendo alcançar, em sistemas mais avançados, valores superiores a 100kg/ha (Sebrae/Senar/Farsul, 2005; Carvalho et al., 2006). Resultados de produtividades semelhantes com pastagens hibernais sem irrigação foram encontrados por Restle et al. (1998) e Roso e Restle (2000), com valores respectivos de 669 e $726 \mathrm{~kg} / \mathrm{ha}$. Esses resultados indicam o potencial das forrageiras para a produção de carne, mesmo sem a tecnologia da irrigação, objeto deste estudo.

A intensificação da produção forrageira com sistemas de irrigação tem aumentado nos últimos anos (Alencar et al., 2009), apesar de a tecnologia apresentar um alto valor de implantação. O principal fator determinante para a adoção da técnica é o elevado preço do equipamento (Azevedo e Saad, 2009), que é influenciado diretamente pelo tamanho e pela topografia da área a ser irrigada, o que exige um considerável investimento. No entanto, para viabilizar o sistema, o capital total necessário é ainda maior e envolve custos com implantação e manutenção de pastagens, aquisição de animais e despesas operacionais.

$\mathrm{Na}$ análise do custo total, as contas com maior percentual foram a remuneração do capital (COC) e da terra (COT), a implantação de pastagens e a energia elétrica. $\mathrm{O}$ valor elevado da COC é decorrente, principalmente, do valor investido em animais, além dos elevados valores para operacionalização do sistema.

No custo médio (operacional) dos três sistemas produtivos, o item mais representativo foi $o$ estabelecimento da pastagem, sendo os fertilizantes e a mecanização as despesas mais relevantes. A manutenção da pastagem, a adubação de cobertura e a mecanização agrícola foram a terceira maior conta que, somada ao custo de estabelecimento, representou $51 \%$ do custo operacional médio. Esse percentual reflete a representatividade dos custos com pastagens nesse tipo de sistema produtivo, pois permite afirmar que apenas a presença do sistema de irrigação não assegura maior produção de massa de forragem se as pastagens não forem de alto potencial para crescimento, e o solo devidamente corrigido e fertilizado.

A produção de pastagem cultivada de inverno apresenta elevado custo de estabelecimento, e a sua eficiência é dependente da fertilidade do solo (Alves Filho et al., 2003). Segundo Restle et al. (1999), os recursos em fertilizantes devem ser usados de forma racional, a fim de aumentar a sua eficiência e otimizar o custo final de produção. No entanto, Cunha et al. (2008) lembram que as pastagens têm um menor custo de produção em relação aos concentrados, sendo, portanto, a forma mais prática e econômica de alimentação dos bovinos.

A energia elétrica representou o segundo maior valor do custo operacional médio. Essa conta tem valor significativo e constitui um dos principais componentes na composição dos custos de produção em sistemas irrigados (Andrade Júnior et al., 2001; Alencar et al., 2009). Apesar de ser uma despesa variável, é dependente da eficiência do sistema e da energia necessária para transportar água do local de captação até a área irrigada (Scaloppi, 1985). Conforme Lima et al. 
(2009), a redução dessa despesa é possível em pivô central, desde que haja um adequado dimensionamento do equipamento de irrigação no momento da sua implantação, o que promove uma melhor eficiência energética na utilização dele. De outra parte, a maximização do uso da energia em relação aos horários de uso pode ser um elemento importante na composição do custo final desse fator.

Segundo Alencar et al. (2009), em pastagens irrigadas com pivô central, o custo do equipamento representa um elevado valor. Em concordância com o autor, no presente trabalho a depreciação foi um item significativo e contabilizou $12 \%$ do custo operacional médio, sendo o quarto item de maior valor avaliado.

$\mathrm{Na}$ avaliação financeira, todos os sistemas registraram resultados positivos para a $\mathrm{MB}$, o que evidencia que a remuneração foi suficiente para pagar os custos desembolsáveis, constituindo um indicador de eficiência do sistema no curto prazo (Figueiredo et al., 2007). $\mathrm{Na}$ avaliação da $\mathrm{MO}$, os sistemas S2 e S3 apresentaram valores positivos, mostrando que houve remuneração dos custos desembolsáveis e da depreciação. Esses resultados indicam a eficiência da atividade sob uma perspectiva de médio prazo (Lopes e Carvalho, 2002). Com relação ao $\mathrm{LT}$, somente o $\mathrm{S} 2$ obteve resultado positivo, com remuneração dos custos desembolsáveis, da depreciação e de oportunidade, o que indica uma eficiência de longo prazo e comprova a viabilidade econômica da atividade (Figueiredo et al., 2007).

Os valores encontrados para o custo total por $\mathrm{kg}$ produzido e por hectare (Tab. 1) mostram a magnitude do custo de oportunidade, sobretudo sobre o S1. Quando se retira esse indicador de eficiência econômica, os custos diminuem consideravelmente, fazendo com que a lucratividade dos sistemas aumente.

Os resultados negativos registrados na avaliação financeira são explicados, majoritariamente, pelas menores produtividades encontradas. Segundo Drumond e Aguiar (2005), em pastagens irrigadas, tal fato está relacionado à inabilidade de técnicos e produtores e à falta de tecnologias no manejo delas.
A LUC e a RCI são importantes indicadores na avaliação financeira da atividade pecuária. Ambos os parâmetros foram obtidos somente para os sistemas que apresentaram resultados positivos para MO (S2 e S3). Os valores encontrados da LUC são satisfatórios e demonstram que a tecnologia avaliada pode ser uma alternativa economicamente viável, possibilitando a capitalização do empresário.

Quanto à RCI, índice que permite comparar o rendimento com outras opções de mercado (Nogueira, 2007), os sistemas estudados apresentaram valores menores que a poupança, a qual finalizou o ano de $2011 \mathrm{em} \mathrm{7,5 \% .} \mathrm{Ou} \mathrm{seja,}$ se todo o capital imobilizado para viabilizar os sistemas produtivos tivesse sido aplicado na caderneta de poupança, o rendimento seria superior. Entretanto, por ser a pecuária uma atividade de baixa rentabilidade, a intensificação dos processos produtivos surge como uma alternativa para melhoria desse indicador.

$\mathrm{Na}$ análise do tempo de retorno do capital investido (payback), os valores encontrados foram de 4,21 anos para o S2 e 6,99 anos para o S3. Esses períodos estão próximos dos valores comentados por Azevedo e Saad (2009), que consideraram satisfatórios os resultados de 2,9 anos (região Nordeste) e 5,4 anos (CentroOeste).

O ponto de equilíbrio ou nivelamento reflete a igualdade entre os custos operacionais e as receitas, sendo um importante parâmetro para avaliação econômica de projetos. Nos sistemas estudados, o ponto de equilíbrio indicou viabilidade dos sistemas produtivos a partir das produções de $37.317 \mathrm{~kg}$ para o $\mathrm{S} 2$ e $36.231 \mathrm{~kg}$ para o $\mathrm{S} 1$. Ou seja, representa o momento em que a atividade começa a ter lucro financeiro e ultrapassa o custo operacional. $\mathrm{Na}$ segunda simulação, a receita unitária mínima para igualar os custos operacionais e evitar prejuízos é de $\mathrm{R} \$$ 1,86 e $2,25 / \mathrm{kg}$, respectivamente, para o $\mathrm{S} 2$ e S3 (Fig. 2). Essa informação é relevante para o empresário rural, pois mostra exatamente qual o preço mínimo que pode trabalhar para que a sua atividade obtenha lucros. 


\section{CONCLUSÃO}

A viabilidade econômica da irrigação de pastagem para a terminação de bovinos foi comprovada com o resultado de lucro total encontrado no sistema S3. No entanto, os resultados dos sistemas $\mathrm{S} 2$ (margem operacional) e S1 (margem bruta) remetem para a importância de se obterem altas produtividades a fim de compensar os elevados custos da tecnologia. Apesar de ser de alto risco, a irrigação é uma ferramenta importante para a intensificação da produção animal, devendo o seu uso ser bem planejado. Além disso, há a necessidade de conhecimento prévio de algumas variáveis que influenciam o resultado final, tais como: manejo de pastagens, irrigação, escolha de animais com elevado potencial produtivo e capacidade gerencial. A análise econômica é fundamental para avaliar a sustentabilidade das empresas rurais, não sendo diferente para tecnologias inovadoras, como é o caso da irrigação de pastagens. É relevante que outros trabalhos também avaliem o seu retorno econômico para validar a sua adoção e para a melhor e mais adequada utilização dos recursos.

\section{REFERÊNCIAS}

ALENCAR, C.A.B.; CUNHA, F.F.; MARTINS, C.E. et al. Irrigação de pastagens: atualidade e recomendações para uso e manejo. Rev. Bras. Zootec., v.38, p.98-108, 2009.

ALVES FILHO, D.C.; NEUMANN, M.; RESTLE, J. et al. Características agronômicas produtivas, qualidade e custo de produção de forragem em pastagem de azevém (Lolium multiflorum Lam) fertilizada com dois tipos de adubo. Cienc. Rural, v.33, p.143-149, 2003.

ANDRADE JÚNIOR, A.S.; FRIZZONE, J.A.; BASTOS, E.A. et al. Estratégias ótimas de irrigação para a cultura da melancia. Pesq. Agropec. Bras., v.36, p.301-305, 2001.

AZEVEDO, L.P.; SAAD, J.C.C. Irrigação de pastagens via pivô central, na bovinocultura de corte. Irriga, v.14, p.492-503, 2009.

BARBOSA, F.A.; GRAÇA, D.S.; ANDRADE, V.J. et al. Produtividade e eficiência econômica de sistemas de produção de cria, recria, e engorda de bovinos de corte na região sul do estado da Bahia. Arq. Bras. Med. Vet. Zootec., v.62, p.677-685, 2010.
BONACCINI, L.A. A nova empresa rural. Cuiabá: Sebrae-MT, 2000. 141p.

CARVALHO, P.C.F.; FISCHER, V.; SANTOS, D.T. et al. Produção animal no bioma campos sulinos. Rev. Bras. Zootec., v.35, p.156-202, 2006. (supl. especial).

COSTA, L.B.; CERETTA, P.S.; GONÇALVES, M.B.F. Viabilidade econômica: análise da bovinocultura de corte. Inform. Econ., v.36, p.26-38, 2006.

CUNHA, F.F.; SOARES, A.A.; MONTOVANI, E.C. et al. Produtividade do capim tanzânia em diferente níveis e frequências de irrigação. Acta Sci. Agro., v.30, p.103-108, 2008.

DRUMOND, L.C.D.; AGUIAR, A.P.A. Irrigação de pastagem. Uberaba: L.C.D. DRUMOND, 2005. 210p.

FIGUEIREDO, D.M.; OLIVEIRA, A.S.; SALES, M.F.L. et al. Análise econômica de quatro estratégias de suplementação para recria e engorda de bovinos em sistema pastosuplemento. Rev. Bras. Zootec., v.36, p.14431453, 2007.

FLORES, A.W.; RIES, L.R.; ANTUNES, L.M. Gestão rural. Porto Alegre: Ed. dos Autores, 2006. 328p.

FRANKE, A.E.; DORFMAN, R. Viabilidade econômica da irrigação, sob condições de risco, em regiões de clima subtropical. Pesq. Agropec. Bras., v.33, p.2003-2013, 1998.

INSTITUTO Nacional de Meteorologia INMET. Normais climatológicas do Brasil 19611990. In: RAMOS, A.M.; SANTOS, L.A.R.; FORTES, L.T. (Eds). Brasília: Editora Brasília, 2009. 465p.

LIMA, A.C.; GUIMARAES JÚNIOR, S.C.; FIETZ, C.R.; CAMACHO, J.R. Avaliação e análise da eficiência energética na irrigação em sistemas pivô central. Rev. Bras. Eng. Agríc. Ambient., v.13, p.499-505, 2009.

LOPES, M.A.; CARVALHO, F.M. Custo de produção de gado de corte. Lavras: UFLA, 2002. $47 \mathrm{p}$.

MATSUNAGA, M.; BEMELMANS, P.F.; TOLEDO, P.E.N. et al. Metodologia de custo de produção utilizado pelo IEA. Agri. São Paulo, v.23, p.123-139, 1976 
NOGUEIRA, M.P. Gestão de custos e avaliação de resultados: agricultura e pecuária. 2.ed. Bebedouro: Scot Consultoria, 2007. 244p.

PACHECO, P.S.; RESTLE, J.; VAZ, F.N. et al. Avaliação econômica da terminação em confinamento de novilhos jovens e superjovens de diferentes grupos genéticos. Rev. Bras. Zootec., v.35, p.309-320, 2006.

RESTLE, J.; LUPATINI, G.C.; ROSO, G.; SOARES, A.B. Eficiência e desempenho de categorias de bovinos de corte em pastagem cultivada. Rev. Bras. Zootec., v.27, p.397-404, 1998.

RESTLE, J.; BRONDANI, I.L.; BERNARDES, R.A.C. O novilho superprecoce. In: RESTLE, J. (Ed.). Confinamento, pastagens e suplementação para produção de bovinos de corte. Santa Maria: UFSM, 1999. p.191-214.

ROSO, C.; RESTLE, J. Aveia preta, triticale e centeio em mistura com azevém. Produtividade animal e retorno econômico. Rev. Bras. Zootec., v.29, p.85-93, 2000.
SCALOPPI, E.J. Exigências de energia para irrigação. ITEM - Irrigação e Tecnologia Moderna, v.21, p.13-17, 1985.

SEBRAE/SENAR/FARSUL. Diagnóstico de sistemas de produção de bovinocultura de corte no estado do Rio Grande do Sul. Porto Alegre: SENAR, 2005. 265p.

SILVA, R.R.; PRADO, I.N.; CARVALHO, G.G.P. et al. Níveis de suplementação na terminação de novilhos Nelore em pastagens: aspectos econômicos. Rev. Bras. Zootec., v.39, p.2091-2097, 2010.

UGHINI. S.; PIRES, J.L.; CUNHA, G.R. et al. Sinais de mudanças no regime de chuvas no Estado do Rio Grande do Sul durante o século 20. In: CONGRESSO BRASILEIRO DE AGROMETEOROLOGIA, 14., 2005, Campinas. Anais... Campinas: UNICAMP, 2005. p.106. 